\title{
Reliable characterization of organic dielectrics degraded by high electric field
}

\author{
Djamila Abid ${ }^{1}$, Hocine Hadi $^{2}$, Boulos Youssef ${ }^{3}$, Mohammed Benzohra ${ }^{4}$ \\ ${ }_{1,2}$ Department of Electric Engineering, University of Sciences and Technology of Oran, Algeria \\ ${ }^{3}$ PBS Laboratory, UMR 6270, FR 3038 CNRS, INSA Rouen, France \\ ${ }^{4}$ Department Networks and Telecommunications, University of Rouen, France
}

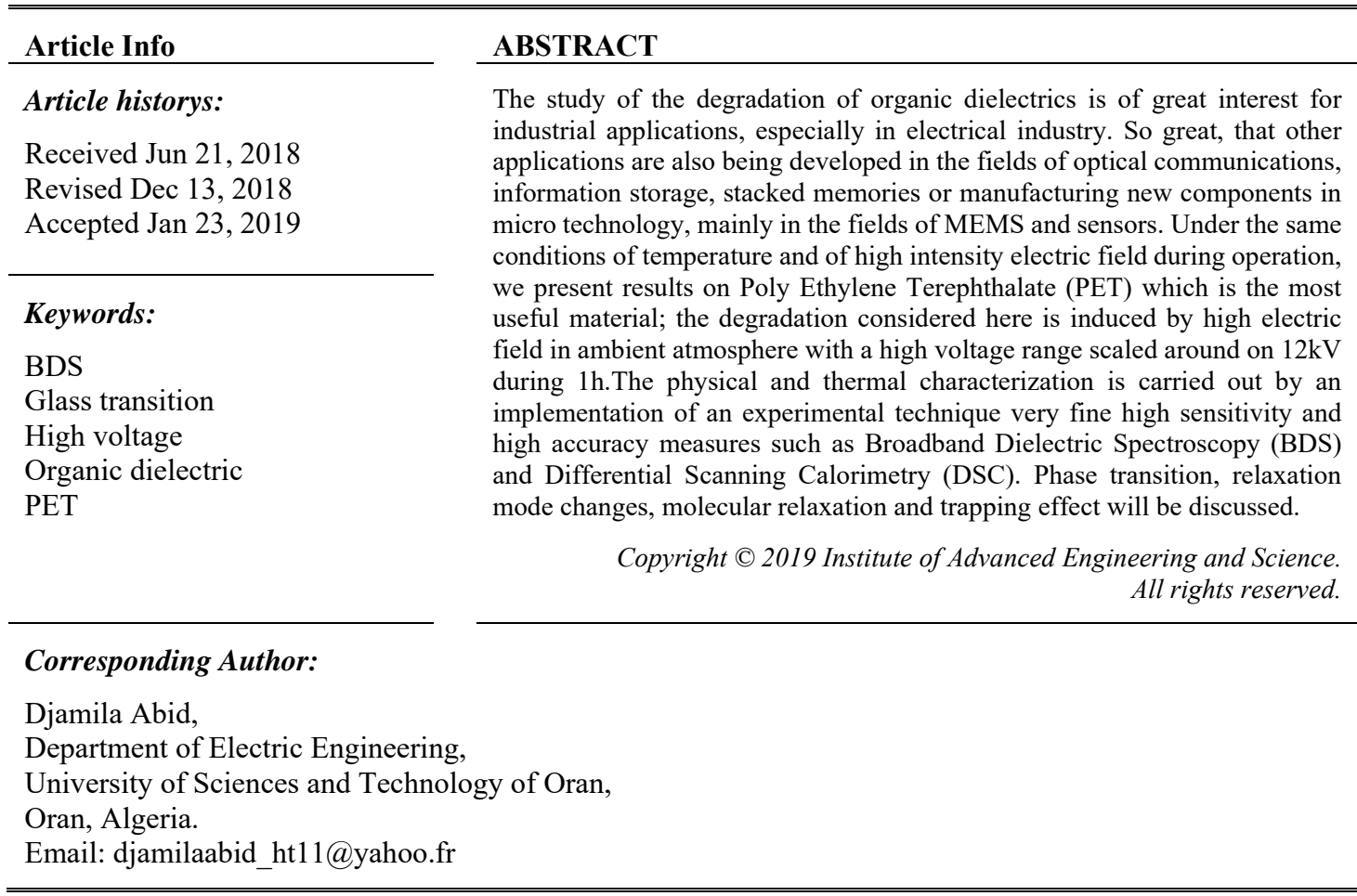

\section{INTRODUCTION}

In electrical industry, whether in insulating parts, where a thin layer organic polymer-based is more and more introduced between two conductive and semiconductor layers [1], or in medium and high voltage power cables, andevenin waveguide structures [2], organic dielectrics are subjected to physical and thermal stresses that degrade their properties and hence their performances [3]-[5]. This degradation is accompanied by phenomena of structural relaxation named physical aging [6] or modification of the chemical structure of the chain named chemical aging [7], [8]. Characterization of degraded organic dielectrics is then necessary for the design and dimensioning of the insulating structures. Today, research focuses on some organic dielectrics used or will be used in electrical industry taking account of the bioethical standards currently in force. The degradation considered here is associated with the specific operating conditions in the electrical industry [9]; it was carried out in the High Voltage Laboratory (L.T.H.) of the University of Science and Technology of Oran. (U.S.T. Oran) and is induced by high electric field in ambient atmosphere with a high voltage range scaled around on $12 \mathrm{kV}$.

Among the polymers most studied in this field are thermoplastics, silicones, polyepoxides and other thermosetting polymers. We present here the results on thePoly Ethylene Terephthalate PET which has a low dissipation factor 0.002 and a dielectric constant of $\varepsilon r=3.3$; Furthermore stretching can improve its mechanical strength and dimensional stability and increase its high frequency properties [10], [11].The physical and thermal characterization is carried out by an implementation of an experimental technique very fine high 
sensitivity and high accuracy measures such as Broadband Dielectric Spectroscopy (BDS) and Differential Scanning Calorimetry (DSC). The equipment used is very efficient; it will allow the acquisition of more reliable measurements than before and thus induce an improvement of the characterization. The analysis will exploit the latest knowledge on organic dielectrics. The analysis focuses here on the comparison of a PET nondegraded sample and an irradiated PET sample to precisely show at a same time the sensitivity, accuracy of the measurements and the effects of high electric field on an organic dielectric. Phase transitions, relaxation mode changes, molecular relaxation and shape modification and trap effect will be discussed.

\section{MATERIALS AND METHODS}

The BDS method is becoming a strong tool for the analysis of molecular dynamics in short and longdistance charges and transport in polymers [12]. Its principle is based on the application of a sinusoidal voltage at a sample located among two metal electrodes and the analysis of the amplitude and phase of the electrical response of the material [13]. In our case the Alpha analyzer from Novocontrol covers a wide frequency range between $10^{-1}$ and $210^{6} \mathrm{~Hz}$ and we shall focus only on the analysis based on the measure of the frequency response, and the temperature response acquired isothermally in a range from to $-150{ }^{\circ} \mathrm{C}$ to $50{ }^{\circ} \mathrm{C}$.

To analyze dielectric relaxation curves, Havriliak-Negami (HN) complex function was used [14].

$$
\varepsilon^{*}(\omega)=\varepsilon_{\infty}+\frac{\Delta \varepsilon_{\mathrm{HN}}}{\left[1+\left(\mathrm{i} \omega \tau_{\mathrm{HN}}\right)^{\alpha} \mathrm{HN}\right]^{\beta_{\mathrm{HN}}}}
$$

the real $\left(\varepsilon^{\prime}(\omega)\right)$ and imaginary parts $\left(\varepsilon^{\prime \prime}(\omega)\right)$ of the complex dielectric permittivity $\left(\varepsilon^{*}(\omega)\right)$ are fitted with the following (1)-(4):

$$
\begin{aligned}
& \varepsilon^{\prime}(\omega)=\varepsilon_{\infty}+\Delta \varepsilon_{\mathrm{HN}} \times \frac{\cos \left(\beta_{\mathrm{HN}} \varphi_{\mathrm{HN}}\right)}{\left(1+2 \sin \left(\frac{\pi\left(1-\alpha_{\mathrm{HN}}\right)}{2}\right)\left(\omega \tau_{\mathrm{HN}}\right)^{\alpha} \mathrm{HN}+\left(\omega \tau_{\mathrm{HN}}\right)^{2 \alpha_{\mathrm{HN}}}\right)^{\beta_{\mathrm{HN}} / 2}} \\
& \boldsymbol{\varepsilon}^{\prime \prime}(\boldsymbol{\omega})=\Delta \boldsymbol{\varepsilon}_{\mathrm{HN}} \times \frac{\sin \left(\beta_{\mathrm{HN}} \varphi_{\mathrm{HN}}\right)}{\left(1+2 \sin \left(\frac{\pi\left(1-\alpha_{\mathrm{HN}}\right)}{2}\right)\left(\omega \tau_{\mathrm{HN}}\right)^{\alpha} \mathrm{HN}+\left(\omega \tau_{\mathrm{HN}}\right)^{2 \alpha_{\mathrm{HN}}}\right)^{\beta_{\mathrm{HN} / 2}}}
\end{aligned}
$$

with

$$
\varphi_{\mathrm{HN}}=\arctan \left(\frac{\left(\omega \tau_{\mathrm{HN}}\right)^{\alpha_{\mathrm{HN}} \cos \left(\frac{\pi\left(1-\alpha_{\mathrm{HN}}\right)}{2}\right)}}{1+\left(\omega \tau_{\mathrm{HN}}\right)^{\alpha} \mathrm{HN} \sin \left(\frac{\pi\left(1-\alpha_{\mathrm{HN}}\right)}{2}\right)}\right)
$$

where $\omega$ is the angular pulsation, $\Delta \varepsilon_{H N}$ the relaxation strength of relaxation, $\tau_{H N}$ the relaxation time and $\alpha_{H N}$ and $\beta_{H N}$ the symmetric and asymmetric broadening factor. To study the effect of the electric field on the PET we applied a voltage on sample as shown in Figure 1.

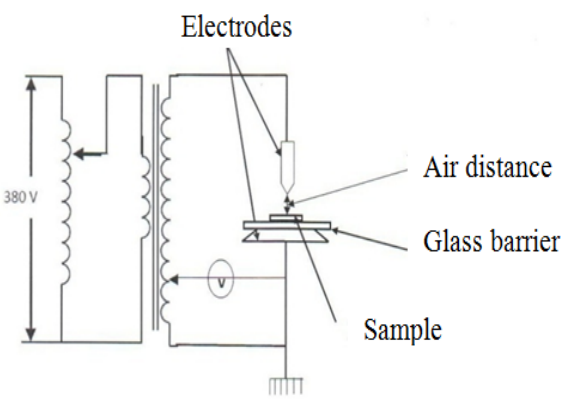

Figure 1. Experimental degradation device

The electrical discharge is obtained by the point - to - plane system. The whole is placed in the air. The terminals of the flat electrode are rounded to $3 \mathrm{~cm}$ in diameter to avoid edge effects. The high-voltage electrode is a cylinder of $10 \mathrm{~mm}$ diameter which ends in a tip of $0.5 \mathrm{~mm}$ diameter of curvature. The tip electrode is connected to the AC high voltage terminal of the test transformer, and the electrode is grounded.

Reliable characterization of organic dielectrics degraded by high electric field (Djamila Abid) 
In order to subject a sample of small thickness to the electrical stress, we will place a glass disk of thickness $5 \mathrm{~mm}$; this glass constitutes a dielectric barrier whose role is to avoid the arc of the discharge between the two electrodes.

To do this we used a sample of poly (ethylene terephthalate) (PET) film supplied by the company Carolex and stored in air and at ambient temperature. The form of a film is thickness $130 \mu \mathrm{m}, 20 \mathrm{~mm}$ in diameter, transparent color and flexible. The PET sample is placed in series with an air distance of 5 millimeter so that the channel of the discharge concentrates on the sample. This sample is then irradiated for 1 hour by an electric field at $12 \mathrm{kV}$.

The technique adopted for the structural characterization of PET is Differential Scanning Calorimetry (DSC). The DSC is a very fine technique allowing, from its thermo grams, to measure the temperatures of thermal vitreous transition $\mathrm{Tg}$, crystallization $\mathrm{Tc}$ and fusion $\mathrm{Tf}$ as well as to calculate the enthalpies of fusion $\Delta \mathrm{H}_{\mathrm{f}}$ and crystallization $\Delta \mathrm{H}_{\mathrm{c}}$ with:

$$
\begin{aligned}
& \Delta \mathrm{H}_{\mathrm{c}} \text { or } \\
& \Delta \mathrm{H}_{\mathrm{f}}=\mathrm{H}_{\mathrm{f}}-\mathrm{H}_{\mathrm{i}}=\int_{\mathrm{i}}^{\mathrm{f}} \mathrm{C}_{\mathrm{p}}(\mathrm{T}) \mathrm{dT}
\end{aligned}
$$

Where $\mathrm{f}$ and $\mathrm{i}$ are respectively the final state (liquid) and the initial state (solid) and $\mathrm{Cp}(\mathrm{T})$ the thermal capacity of the material. $\Delta \mathrm{H}_{\mathrm{c}}$ and $\Delta \mathrm{H}_{\mathrm{f}}$ for respectively the exothermic and endothermic peaks.

By exploiting the areas of the peaks, the DCS also makes it possible to determine the percentage of the crystalline phase as well as that of the amorphous phase in the semi-crystalline polymer.

$$
\mathrm{X}_{\mathrm{a}}=\frac{\Delta \mathrm{C}_{\mathrm{P}}}{\left(\Delta \mathrm{C}_{\mathrm{p}}\right)_{\mathrm{a}}}
$$

with $\left(\Delta \mathrm{c}_{\mathrm{p}}\right)_{\mathrm{a}}$ determined experimentally through a test conducted on amorphous PET and equal to $0.396 \mathrm{~J} / \mathrm{g}^{\circ} \mathrm{C}$ and

$$
X_{c}=\frac{\Delta H_{f}-\Delta H_{c}}{\left(\Delta H_{f}\right)_{c}=1}
$$

with $\left(\Delta \mathrm{H}_{\mathrm{f}}\right)_{\mathrm{c}=1}$ is taken to be $117 \mathrm{~J} / \mathrm{g}$ according to [1]

The determination of these parameters will be used also to characterize the effect of the electric field on our irradiated sample.

The DSC tests are carried out on an apparatus of the type Perkin-Elmer Instruments DSC 8000 in the air with cooling with liquid nitrogen. Low mass samples $(\sim 7 \mathrm{mg})$ are weighed by a high precision scale Mettler Toledo MX5. The polymers are warmed from $0^{\circ} \mathrm{C}$ to $300{ }^{\circ} \mathrm{C}$ with a heating rate of $10^{\circ} \mathrm{C} / \mathrm{min}$.

\section{RESULTS AND DISCUSSIONS}

\subsection{Blank PET}

In this experiment we measured the dielectric parameters, dielectric constant $\varepsilon^{\prime}$ and loss factor $\varepsilon^{\prime}$, in the full range of the frequency and for temperature ranging between $49.9{ }^{\circ} \mathrm{C}$ to $118^{\circ} \mathrm{C}$. Figure 2 and Figure 3 show two relaxation peaks identified as $\alpha$ and secondary $\beta$ relaxation peaks. The main $\alpha$ relaxation peak which appears at $\mathrm{T}=79.8^{\circ} \mathrm{C}$ for $\mathrm{f}=0.1 \mathrm{~Hz}$ and it migrates towards the high frequencies gradually as the temperature increases. This displacement is accompanied by a decrease of its amplitude from 0.43 to 0.34 between $108{ }^{\circ} \mathrm{C}$ and $110^{\circ} \mathrm{C}$; the PET is in its amorphous state [15]. Between $108{ }^{\circ} \mathrm{C}$ and $114{ }^{\circ} \mathrm{C}$, the amplitude of the peak decrease roughly from 0.34 to 0.22 in a wide range of frequencies close to $10^{5} \mathrm{~Hz}$.

This is attributed [16] to the phenomenon of crystallization of PET because the presence of the crystalline zones reduces the mobility of the entities responsible for conduction. For higher frequencies ( $\mathrm{f}>$ $10^{3} \mathrm{~Hz}$ ) and for a temperature range from $49.9^{\circ} \mathrm{C}$ to $73.9^{\circ} \mathrm{C}$, we observe the secondary $\beta$ relaxation peak.

These two figures show that the PET has a dielectric stability up to the temperature $69^{\circ} \mathrm{C}$ for the low frequencies of $0.1 \mathrm{HZ}$ up to $1000 \mathrm{HZ}$, indeed no variation for the dielectric parameters, dielectric constant $\varepsilon$ 'and loss factor $\varepsilon$ ' '.

The Figure 4 represents the variation of the loss factor $\varepsilon$ " as a function of the frequency; When the temperature varies from $49.9^{\circ} \mathrm{C}$ to $67.9^{\circ} \mathrm{C}$, the intensity decreases with increasing temperature. This is justified by the participation of water molecules in secondary relaxation [17].

Indo. J. Elec. Eng. \& Inf, Vol. 7, No. 1, March 2019: 76 - 83 


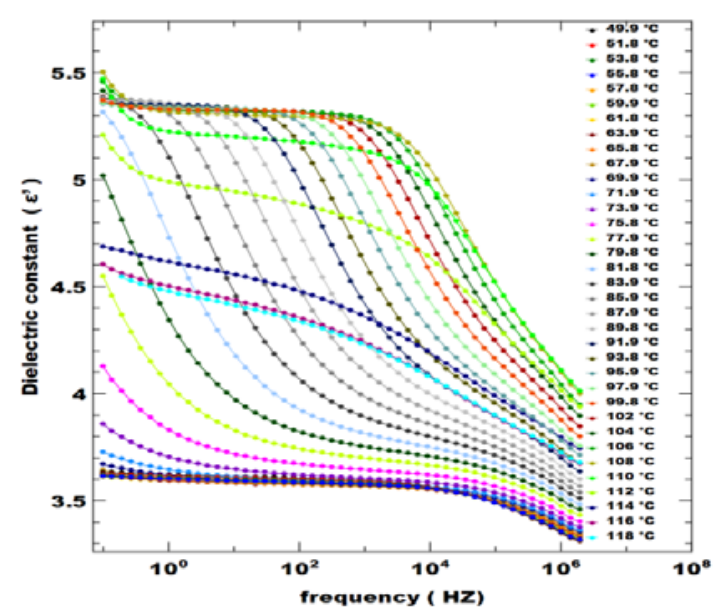

Figure 2. Dielectric constant with frequency: blank PET

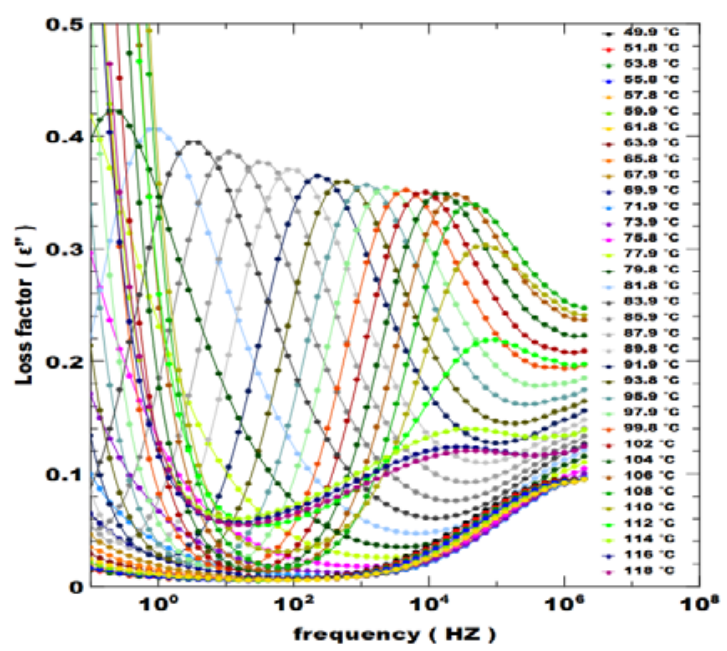

Figure 3. Loss factor with frequency: blank PET

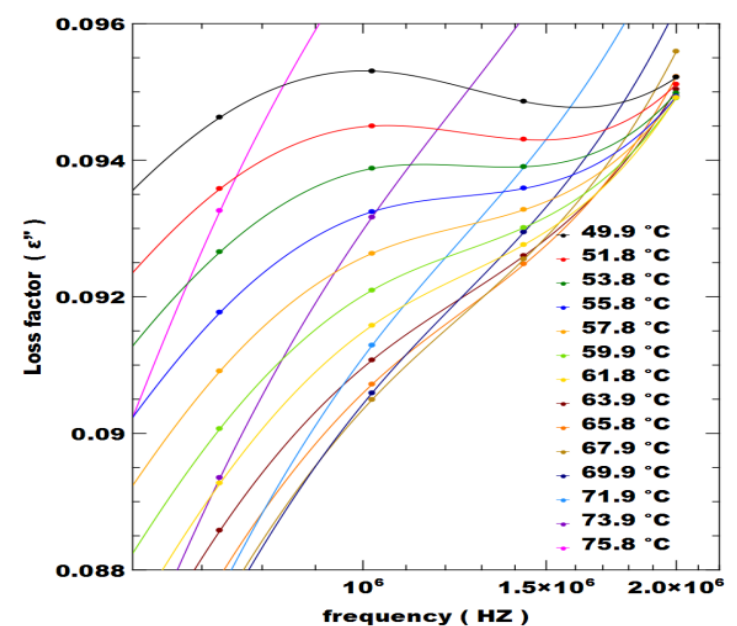

Figure 4. Loss factor with frequency: for the temperature varies between $49.9^{\circ} \mathrm{C}$ and $75.8^{\circ} \mathrm{C}$. blank PET. 
For high temperatures (between $91.9^{\circ} \mathrm{C}$ and $108^{\circ} \mathrm{C}$ ) and low frequencies Figure 5 shows an increase in the dielectric loss factor. This increase is due to the phenomenon of conduction. Straight lines of slope -1 are characteristic of an ohmic conduction.

The result of the differential enthalpy analysis of the PET film in the temperature range $0{ }^{\circ} \mathrm{C}$ to 300 ${ }^{\circ} \mathrm{C}$ is illustrated in Figure 6. It shows a thermo gram of a PET which has two points of inflection, one in zone 1 at a temperature of $83{ }^{\circ} \mathrm{C}$, namely the glass transition temperature. At the temperature of $150^{\circ} \mathrm{C}$. there is another inflection point, in zone 2 , corresponding to the recrystallization temperature. The absence of a recrystallization peak indicates that the sample has a high crystallization rate. Thus, the absence of a peak at the glass transition indicates that the non-irradiated sample is in a metastable equilibrium state. An endothermic peak appears at the temperature $245{ }^{\circ} \mathrm{C}$ corresponding to the melting temperature of the crystals. The blank PET is therefore thermally stable up to $232^{\circ} \mathrm{C}$.

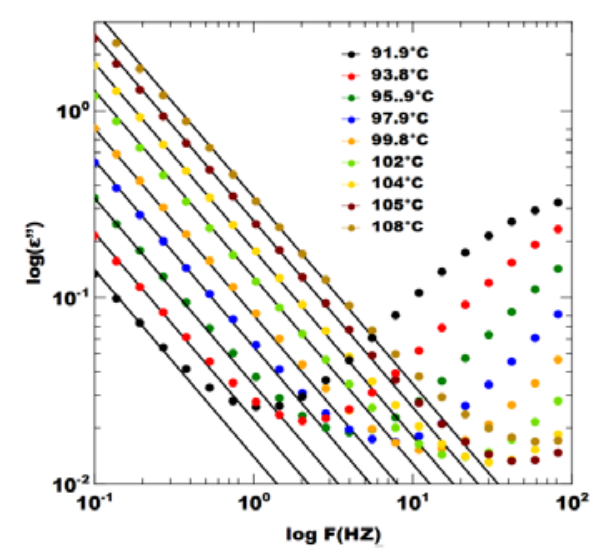

Figure 5. Loss factor with frequency: for the temperature varies between $91.9^{\circ} \mathrm{C}$ and $108^{\circ} \mathrm{C}$. blank PET.

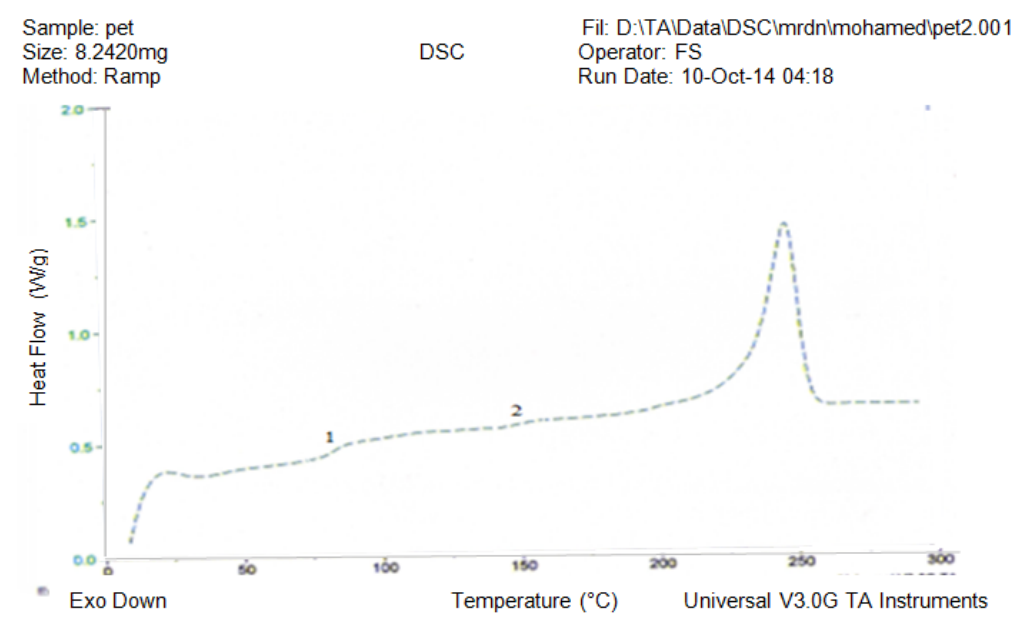

Figure 6. DSC: blank PET

\subsection{Irradiated PET}

The Figure 7 shows the thermo gram of the irradiated PET where we can see the effect of the electric field on the structure of the PET. Zone 1 is the glass-transition region, there is a peak characterizing physical aging or structural relaxation of PET [18], [19]. The glass transition temperature is $77^{\circ} \mathrm{C}$.

Figure 7 shows also that PET, when under irradiation, becomes unstable [20] and [21]. In zone 2, an exothermic peak characteristic of the crystallization of a material is seen. The crystallization temperature is at $\mathrm{T}=150{ }^{\circ} \mathrm{C}$. The second endothermic peak at $245^{\circ} \mathrm{C}$ corresponds to the melting temperature.

Indo. J. Elec. Eng. \& Inf, Vol. 7, No. 1, March 2019: 76 - 83 
The Table 1 below presents the comparison of the structural characteristics measured in DSC of the blank PET and the irradiated PET at $12 \mathrm{KV}$ for 1 hour. The irradiated PET which has a semi crystalline structure with Xc equal to $16.8 \%$. Blank PET is more amorphous with Xa equal to $91 \%$.

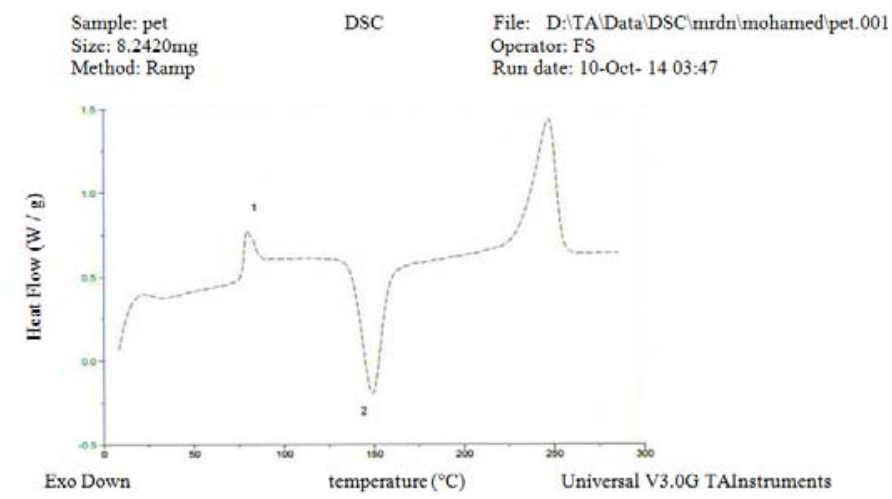

Figure 7. DSC: irradiated PET

Table 1. PET: Structural characteristics from DSC

\begin{tabular}{lllllllll}
\hline & $\mathrm{Tg}^{\circ} \mathrm{C}$ & $\mathrm{Tc}^{\circ} \mathrm{C}$ & $\mathrm{Tf}^{\circ} \mathrm{C}$ & $\Delta \mathrm{HC} \mathrm{J} / \mathrm{g}$ & $\Delta \mathrm{Hf} \mathrm{J} / \mathrm{g}$ & $\mathrm{Xc} \%$ & $\Delta \mathrm{Cp} \mathrm{J} / \mathrm{g}^{\circ} \mathrm{C}$ & $\mathrm{Xa} \%$ \\
\hline Blank PET & 83 & 150 & 245 & 0 & 60.8 & 52 & 0.36 & 91 \\
Irradiated PET & 77 & 150 & 245 & 46.7 & 66.4 & 16.8 & 0.84 & - \\
\hline
\end{tabular}

The decrease in Tg and the increase in $\Delta \mathrm{cp}$ heat capacity jump between non-irradiated PET and irradiated PET is then observed. The decrease in Tg could be the result of chain breaks which have the effect of reducing the number of junction points and thus increasing molecular mobility [22]. In fact, irradiation in the presence of oxygen generally leads to more chain splitting than under neutral gas [23]. The cross linking involves radical coupling, and in a medium rich in oxygen, these molecules react rapidly with the radicals and prevent recombination and therefore the cross linking of the polymer [24].

The appearance of an endothermic peak near the glass transition temperature reflects the physical aging of the irradiated PET as exposed by Vigier [20]. This aging is attributed to the formation of radicals within the amorphous material after irradiation. These radicals are trapped in the vitreous material and can cause slow and gradual changes in the network when maintained at a temperature below the glass transition temperature [25].

We present now the main results obtained by comparing the two types of samples from the BDS analysis. Figure 8 shows the loss factor as a function of frequency for temperatures below the glass transition temperature for irradiated PET.

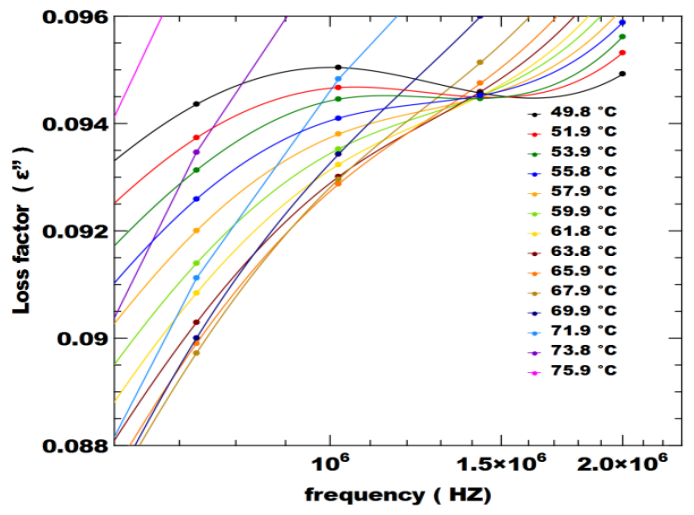

Figure 8. Frequency loss factor for temperatures below the glass transition temperature for irradiated PET 
The values of $\varepsilon "$ are high towards the high frequencies. These values are the consequence of the existence of an extrinsic parasitic series resistance to the sample as suggested by Runt [12]. This increase does not exist for non-irradiated PET as shown in Figure 4. Comparison of the two figures shows closer spectra for irradiated PET that could be associated with a dehydration of PET during irradiation.

Figure 9 shows the relaxation time temperature dependence. We have an Arrhenius trend characterizing molecular localized mobility for the blank PET. And a tendency Vogel-Fulcher-Tammann law characterizing a cooperative mobility of molecules and so a large molecular mobility in the irradiated PET. It would reveal a molecular chain scission due to irradiation.

The isochronous spectrum in Figure 10 reveals a charge injection into the PET after irradiation of 1 hour; it justifies the increase in the amplitude of the peak close to $108^{\circ} \mathrm{C}$ and the appearance of another peak around $116^{\circ} \mathrm{C}$ which represents the peak of the electrode polarization.

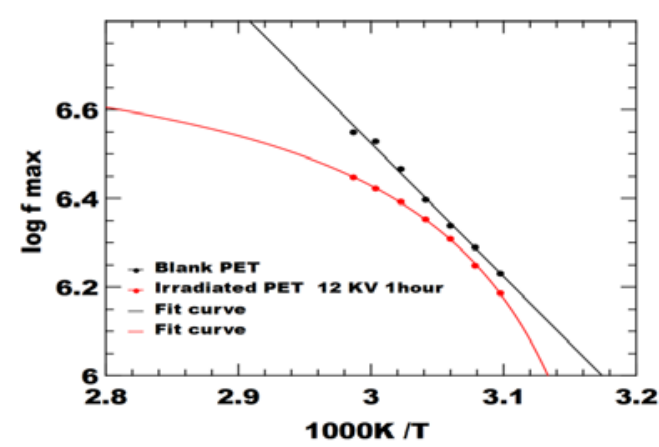

Figure 9. Frequency-Temperature diagram for blank and irradiated PET

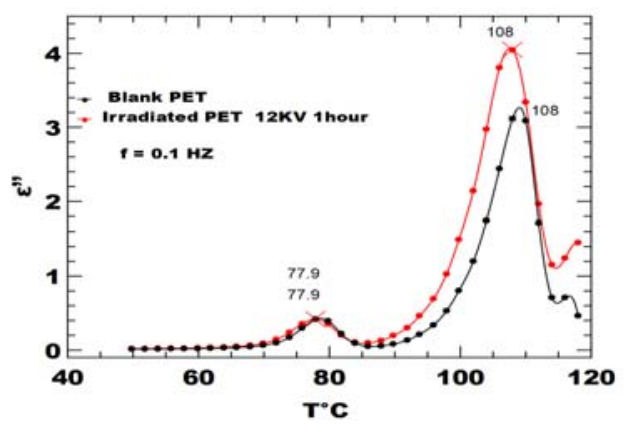

Figure10. Isochronous spectrum of loss factor $\varepsilon "$ at $0.1 \mathrm{~Hz}$ for blank and irradiated PET

\section{CONCLUSION}

The structural, electrical and thermal properties of PET samples are investigated using BDS and DSC measurements with under electric field within the volume of the irradiated samples. The equipment used is very efficient; it will allow the acquisition of more reliable measurements than before and thus induce an improvement of the characterization.

For non-irradiated of PET the measurements show that the water molecules are participated in the $\beta$ secondary relaxation of PET. These samples are then characterized as homogeneous structure, ohmic conduction at high temperature, dielectric stability up to $69^{\circ} \mathrm{C}$ in the frequency range from $0.1 \mathrm{~Hz}$ to $1 \mathrm{KHz}$ and thermal stability up to $\mathrm{T}=232^{\circ} \mathrm{C}$.

Electric field irradiation affects structural properties of PET so that it is characterized in this case by semi-crystalline and heterogeneous structure depending on the phenomenon of charge injection into the volume because it presents a place of trapping for the load to inject. The closer thermal spectra of loss factor for irradiated PET could be associated with a dehydration of PET during irradiation. The tendency Vogel Fulcher - Tammann law in the irradiated PET characterize a cooperative mobility of molecules; it would reveal a molecular chain scission due to electric field irradiation.

Indo. J. Elec. Eng. \& Inf, Vol. 7, No. 1, March 2019: 76 - 83 


\section{REFERENCES}

[1] Allais A, Fournier J, Kebbabi L, Bayon L, Combessis A., "Electric element including a layer of a polymeric material with electrical conductivity gradient," WO Patent, 2013045845, 2013.

[2] Zafar J, Zafar H, zafar T. "Efficient Closed Form Cut-Off Planes and Propagation Planes Characteristics for Boundary-Value Problems," Bulletin of Electrical Engineering and Informatics, vol. 1(2) pp. 89-6, 2012.

[3] Dubau L, Durst J, Castanheira L, Maillard F, Lamibrac A, Dillet J, Maranzana G, Lottin O, ElKaddouri A, De moor G, Bas C, Flandin L, Rossinot E, Caqué N, Chatenet M., "Various Scales of Aging Heterogeneities upon PEMFC Operation-A Link between Local MEA Materials Degradation and the Cell Performance," ECS Transactions, vol. 69(17); 133-146, 2015.

[4] Mackey M, Schuele D, Zhu L, Flandin L, Wolak M, Shirk J, Hiltner A, Baer E., "Reduction of dielectric hysteresis in multilayered films via nanoconfinement," Macromolecules, vol. 45(4), pp. 1954-1962, 2012.

[5] Lukichev A. Graphical method for the Debye-like relaxation spectra analysis. Journal of Non-Crystalline Solids, vol.358(3), pp. 447-720, 2012.

[6] Zhikang T, Bing C, Pei L. "Effects of sub-Tg cross-linking of triptycene-based polyimides on gas permeation, plasticization resistance and physical aging properties," Journal of Membrane Science, vol. 560, pp. 87-96, 2018.

[7] Khelidj N, Colin X, Audouin L, Verdu J, Monchy-Leroy C, Prunie V.,"Oxidation of polyethylene under irradiation at low temperature and low dose rate. Part II. Low temperature thermal oxidation," Polymer Degradation and Stability, vol. 91(7), pp. 1598-1605, 2006.

[8] Dehbi A, Youssef B, Chappey C, Mourad AH, Picuno P, Statuto D., "Multilayers Polyethylene Film for Crop Protection in Harsh Climatic Conditions," Advances in Materials Science and Engineering, 4205862, 2017.

[9] Hafiy M, Zainoddin S, Zainuddin H, Aman A., "Dielectrophoresis Effect of Dielectric Liquids with Suspended Cellulose Impurities under DC Electric Field," International Journal of Electrical and Computer Engineering (IJECE), vol. 7(6), pp. $3254-3261,2017$.

[10] CarrJ M, Mackey M, Flandin L, Schuele D, Zhu L, Baer E., "Effect of biaxial orientation on dielectric and breakdown properties of poly (ethylene terephthalate)/poly (vinylidene fluoride-co-tetrafluoroethylene) multilayer films," Journal of Polymer Science Part B: Polymer Physics, vol. 51(11), pp. 882-896, 2013.

[11] Yin K, Zhou Z, Schuele D E, Wolak M, Zhu L, Baer E., "Effects of Interphase Modification and Biaxial Orientation on Dielectric Properties of Poly(ethylene terephthalate)/Poly(vinylidene fluoride-co-hexafluoropropylene)," $A C S$ Appl. Mater. Interfaces, vol. 8, pp.13555-13566, 2016

[12] Runt J, Fitzgerald J., "Dielectric Spectroscopy of Polymeric Materials, Fundamentals and Applications," American Chemical Society, Washington, DC. 1997.

[13] Williams G., "Dielectric Newsletter," Novocontrol. 1994.

[14] Havriliak S, Negami S. "A complex plane representation of dielectric and mechanical relaxation processes in some polymers," Polymer.vol. 8, pp. 161-210, 1967.

[15] Adachi H, Adachi K, Ishida Y, Kotaka T., "Dielectric relaxation of polydimethylsiloxane," Journal of Polymer Science, vol. 17, pp. 851-857, 1979.

[16] Kao K., "Dielectric phenomena in solids. With emphasis on physical concepts of electronic process," Elsevier Academic press, USA. 2004.

[17] MCCrum NG, Read BE, Williams G., Anelastic and dielectric effects in polymeric solids, John Willey \& Sons, London. 1967.

[18] Hodge IM., "Enthalpy relaxation recovery in amorphous polymers,"0 Journal of Non-Crystalline Solids, vol. 169; pp. 211-266, 1994.

[19] Ki Chul K, Seung Soon J., "Molecular dynamics simulation study on the structural properties of poly (ethylene terephthalate) under uniaxial extension and thermal shrinkage processes," Current Applied Physics, vol. 18, pp. 19-26, 2018.

[20] Vigier G, Tatibouet J., "Physical ageing of amorphous and semi crystalline PET," Polymer, vol. 34, pp. 4257-4266

[21] Perez J., "Physique et mécanique des polymères amorphes," Paris, Lavoisier, vol. 384, 1992.

[22] Ngono Y., "Comportement à long terme des résines thermodurcissables en milieu irradiant : rôle et action de 1'eau. Doctorat thesis," Joseph Fourrier University, Grenoble, vol.196, 1999.

[23] Sonoda K, Enomoto J, Nakazaki K, Murayawa K., "Space radiation effects on mechanical properties of carbon fibre reinforced plastic," Japanese Journal of Applied Physics, vol. 27(11), pp. 2139-2143, 1988.

[24] Gilllen NT, Clough RL., "Quantitative of simple theoretical model for diffusion-limited oxidation," American Chemical Society, pp. 457-472, 1991.

[25] Burnay SG., "Radiation induced structural changes in an epoxide resin system - II Aromatic amine cured system," Radiation Physics and Chemistry, vol. 19(2), pp. 93-99, 1982. 